\title{
Renewed Support Dawns in Europe: An Action to Develop Space Weather Products and Services
}

\author{
Anna Belehaki, Jurgen Watermann, Jean Lilensten, Alexi Glover, Mike Hapgood, Mauro Messerotti, \\ Ronald van der Linden, and Henrik Lundstedt
}

Published 4 March 2009.

Citation: Belehaki, A., J. Watermann, J. Lilensten, A. Glover, M. Hapgood, M. Messerotti, R. van der Linden, and H. Lundstedt, (2009), Renewed support dawns in Europe: An action to develop space weather products and services, Space Weather, 7, S03001, doi:10.1029/2008SW000451.

The effects of space weather span a range of sectors. They can cause radio communications problems; can disrupt synthetic aperture radar systems, the Global Positioning System (GPS), and the future European Galileo systems; and can increase radiation risks for aircraft crew and passengers. Electric power network disturbances and enhanced corrosion effects observed in long-distance fuel supply pipelines are

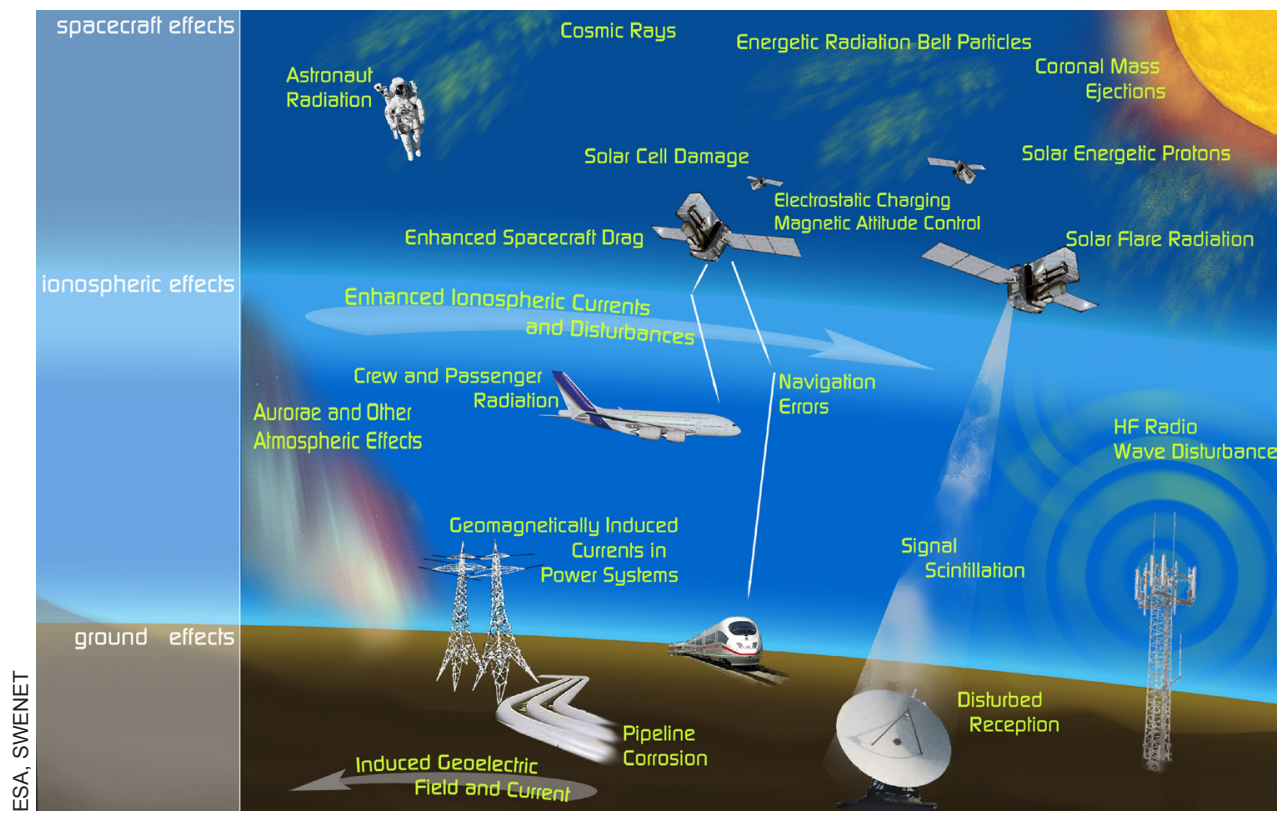

Figure 1. Adverse space weather can affect a broad variety of systems upon which society depends. As more research becomes focused on space weather and more groups are needing and developing services to predict adverse space weather, nations across Europe have joined forces through a newly approved action item within the European Cooperation in Science and Technology (COST) program to advance European space weather science and ensure that research and applications speak a common language. other well-known effects of unfavorable space weather. In severe cases, large-scale power outages have also been traced to space weather phenomena (Figure 1).

Research efforts in various countries-including the U.S. multiagency National Space Weather Program (http:// www.nswp.gov), the International Space Environment Service (ISES; http://www.ises-spaceweather.org/), and several European initiatives sponsored by the European Space Agency (ESA) and the European Commission (EC) - have demonstrated that adverse space weather poses a tangible threat to humans and modern technological systems and assets on the ground, in the air, and in space. Although methods to model some aspects of space weather have been developed by these agencies, all agree that their performance needs to be improved-in many cases, prediction accuracy is inadequate to allow the transition from models to reliable operational services. Further targeted research and development is needed.

Funding for coordinated space weather science and applications effects in Europe has so far been on a project-by-project basis. Systematic national contributions to a pan-European space weather program are not yet in place, leading to fragmentation of European space weather initiatives. A certain level of 
federation of applications and services relating to security of Europe's space assets will be initiated by ESA through its new Space Situational Awareness preparatory program, the planning stages of which began in late 2008. To complement this, coordination among various space weather researchers and links to operational providers are desperately needed as more groups become interested in space weather.

To satisfy these demands, the European space weather community is implementing a newly approved action item within the European Cooperation in Science and Technology (COST) program (http://www.cost.esf.org/). This initiative (COST Action ES0803) will provide crucial support in Europe for coordination of scientific resources focused on the development of underpinning scientific models and tools and will set scientific standards for space weather research with operational products in mind.

\section{Prior COST Space Weather Programs}

With 34 member countries, COST is one of the longestrunning instruments supporting cooperation among scientists and researchers across Europe. COST is also the first and widest European intergovernmental network for coordination of nationally funded research activities. The goal of COST is to ensure that Europe holds a strong position in the field of scientific and technical research for peaceful purposes, by increasing European cooperation and interaction in this field.

COST's new space weather plan builds on the successful work of the past 4 years under COST Action 724, an initiative tasked with developing the scientific basis for monitoring, modeling, and predicting space weather. This first stage of coordinating space weather scientific research at a panEuropean level brought together scientists from 28 countries and helped establish the European space weather research community. As a first step, scientists developed and adopted a definition for space weather:

Space weather is the physical and phenomenological state of natural space environments. The associated discipline aims, through observation, monitoring, analysis and modelling, at understanding and predicting the state of the Sun, the interplanetary and planetary environments, and the solar and non-solar driven perturbations that affect them; and also at forecasting and nowcasting the possible impacts on biological and technological systems. (J. Lilensten and A. Belehaki, Acta Geophys., 57(1), 1-14, 2009)

The project took advantage of a large amount of leading scientific expertise to contribute to a number of significant scientific achievements summarized in the final report (http://www.costes0803.noa.gr/beta/Documents/docs/COST _Action_724-final_report.pdf). In addition, an important outcome of COST 724 was the development of the European
Space Weather Portal (ESWP), which provides catalogs of databases and models along with public outreach material translated into different languages. ESWP also hosts a prototype system with online implementation of selected space weather models.

\section{Need for Broader Coordination in Europe}

As space weather becomes increasingly important to smoothly functioning technological systems, more and more research programs and service providers are springing up throughout Europe to address a broad spectrum of user needs that range from nowcasting and forecasting of the space environment to monitoring currents induced by space weather phenomena in high-latitude power lines. Although significant efforts by networked teams have brought together service providers and users in Europe, leading to the development of important pilot operational systems such as the Space Weather European Network (SWENET) portal and the European Digital Upper Atmosphere Server (DIAS), more coordination is needed to ensure network interoperability.

Funded by ESA and national partners, SWENET provides a centralized access point to service products, a data repository, metrics, and analysis tools that can be applied to the products. It also generates alerts according to userdefined thresholds. The products concern ionospheric, satellite, and ground effects and are accessible via the SWENET portal, http://www.esa-spaceweather.net/swenet. The DIAS project, cofunded by the EC, formed a European ionospheric network and established a digital upper atmosphere server to improve access to ionospheric observations. This improved access is facilitated through a database (http://dias.space.noa .gr) that houses homogenized information and through the development of products that support high-frequency communications systems. Both SWENET and DIAS are prototype systems that deliver specific space weather services and products.

Other important contributions to data exchange and the development of warnings and alerts of solar, ionospheric, and geomagnetic disturbances are supplied by the regional warning centers (RWCs) of ISES, several of which reside in Europe.

Recent assessment studies of user requirements performed as part of SWENET and DIAS, together with ESA's Space Weather Programme Feasibility studies carried out during 1999-2001 and the experiences of European scientists gained from operating RWCs, have clearly demonstrated the need for accurate space weather services. The tools developed to allow provision of these services must further be capable of evolving to satisfy demands posed by increasingly sophisticated technological systems. Such factors were considered as scientists outlined the goals of COST ES0803. 


\section{New COST Action Plan}

COST initiatives are designed to last about 4 years. Thus, when COST 724 was completed, scientists were charged with developing a new COST action plan to help advance space weather research and operations. Whereas COST 724 focused on the development of the scientific basis for space weather monitoring and modeling, this new one-COST ES0803focuses on transitioning from scientific models to reliable operational services through targeted research and development. This initiative will build upon previous work but will be distinct from other programs because it seeks to unite research and operations within set scientific standards.

Specifically, COST ES0803 will continue to establish a strong and coordinated scientific community by fostering closer cooperation among national research activities in Europe, providing a detailed cartography of European activities in geospace research, specifying desired improvements in the performance of models across scientific and technological fields affected by space weather phenomena, and strengthening existing links and interactions among model developers, service providers, and potential users of such services. In addition, the new plan will foster collaboration among the space weather research community, the DIAS network, the ESA space weather applications initiative (interfacing through ESA's Space Weather Working Team), and the European RWC network.

The new plan also has an eye toward smoothing the way for future coordination efforts. It will assess the existing potential within the European scientific community to support operational space weather infrastructure, modeling, service development, and most important, collaborative research. COST ES0803 will also specify requirements for new space weather products and services adapted to the needs of end users and for the validation of prototype nowcasting and prediction schemes for operational use. These prototypes will be tested through the ESWP.

Because the new services must be capable of adapting to technology as it advances, a key task of the new action plan will be to review and evaluate the models currently underpin- ning space weather products and, where necessary, to propose improvements based on current cutting-edge research. It is expected that such review will stimulate new targeted research in related fields, which will then be incorporated into future service products.

The participation of most European countries and the active involvement of internationally recognized experts in this field will give COST ES0803 the legitimacy to issue recommendations to other European and international partners. These may include recommendations to use new products such as specific models validated by the new COST action. The new initiative will also play a key role in building strong links and promoting exchange among scientific data providers, model developers, service providers, and end users of space weather products.

The kickoff meeting of COST ES0803 was held in Brussels, Belgium, on 16-17 November 2008, in conjunction with the Fifth European Space Weather Week (ESWW). The 4-year duration of this initiative will provide scientists with the time needed to build a sustainable framework for coordination in European space weather scientific research beyond the conclusion of this specific action plan.

\section{Working Groups}

COST ES0803 is organized into three working groups, each of which is divided into several subgroups (Figure 2). The first working group (Group 1) is devoted to the assess-

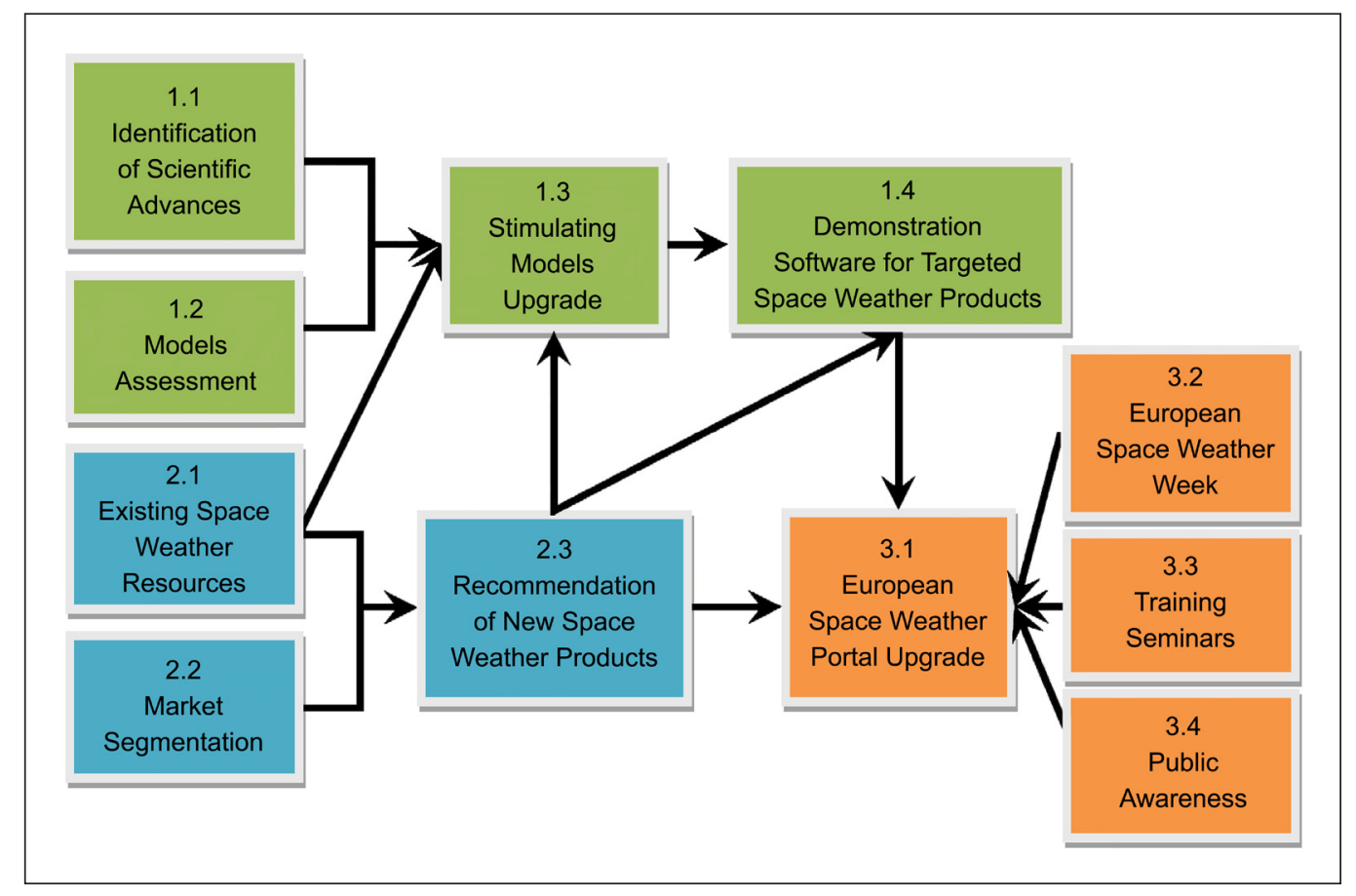

Figure 2. COST Action ES0803 flowchart of working groups. Green represents Group 1, blue represents Group 2, and orange represents Group 3. 
ment and validation of space weather models for research and applications. The major outcome of this group is expected to be recommendations on criteria and metrics for validating space weather models, a list of recommended models, and software codes for establishing targeted space weather products.

The second working group (Group 2) is devoted to specifying requirements for new space weather products and services. This will be achieved by assessing current monitoring capabilities and existing European space weather products and services. A detailed survey of European space weather market requirements will also be conducted.

The third working group (Group 3) is responsible for dissemination, education, and outreach programs. The ESWP, currently accessible via http://www.spaceweather.eu, most likely will be upgraded with key data sets and scientific model codes, some of which could be run interactively or online. In addition and in collaboration with SWENET, new services will likely be made available by transitioning new scientific output generated by this initiative into existing or new user-oriented pilot services. The action plan, in collaboration with the European Space Research and Technology Centre (ESTEC) of ESA, will be one of the main scientific co-organizers of ESWW, which has become the central annual event in Europe, bringing together researchers, service developers, providers, and users in an active dialogue about space weather.

\section{Toward a Coordinated Space Weather Effort}

At present, more than 40 experts from 20 countries have expressed interest in participating in COST ES0803. COST provides funds only for travel and activities supporting coordinated research across national borders. It does not finance research and technological development activities. Even under this strict financing framework, there is strong motivation for a country to participate in a COST action, because these programs are known to set scientific standards for Europe. Further, recommendations made by COST actions to European policy-making organizations and agencies carry the authority of a Europe-wide team of experts.

Scientists and service providers involved with COST ES0803 hope that it will create sustainable links between the European space weather research community and other European and international partners for the development of state-of-the-art space weather research products that support and promote space weather monitoring, modeling, and prediction in Europe.

Anna Belehaki leads the Ionospheric Group at the National Observatory of Athens, in Greece, and is the coordinator of COST ES0803. Jurgen Watermann is a researcher with Le Studium, in Orleans, France. Jean Lilensten is a researcher at the Centre National de la Recherche Scientifique's Laboratoire de Planétologie de Grenoble, in France. Alexi Glover is a member of the Space Environments and Effects section of the European Space Agency and an employee of Rhea System based in Noordwijk, Netherlands, and coordinates the Space Weather European Network. Mike Hapgood leads the Space Environment Group at the Rutherford Appleton Laboratory, in Chilton, United Kingdom. Mauro Messerotti is research astronomer at the National Institute for Astrophysics, in Trieste, Italy. Ronald van der Linden is director general of the Royal Observatory of Belgium, in Brussels, and director of its Solar Influence Data Analysis Service. Henrik Lundstedt leads the Lund Solar and Space Weather Group at the Swedish Institute of Space Physics, in Lund, Sweden, and is deputy director of the International Space Environment Service. 